\title{
On the mechanism of the domino reaction of 2-methyl-2- benzyloxycarbonyl-1-indanone mediated by palladium, hydrogen and aminoalcohols
}

\author{
Caroline Muller, Françoise Hénin, and Jacques Muzart* \\ CNRS-Université de Reims Champagne-Ardenne, Institut de Chimie Moléculaire de Reims, \\ UMR 7312, UFR des Sciences Exactes et Naturelles, BP 1039, 51687 Reims Cedex 2, France \\ E-mail: jacques.muzart@univ-reims.fr
}

Dedicated to Professor Jürgen Martens on the occasion of his $65^{\text {th }}$ birthday

DOI: $\underline{\text { http://dx.doi.org/10.3998/ark.5550190.p008.805 }}$

\begin{abstract}
Whereas the Pd-catalyzed hydrogenolysis of racemic 2-methyl-2-benzyloxycarbonyl-1-indanone in the presence of an unichiral (enantiopure) aminoalcohol leads to optically active 2methylindanone, such a domino reaction using optically active 2-methyl-2-benzyloxycarbonyl-1indanone and an achiral aminoalcohol affords racemic 2-methylindanone. According to these results, the ketone is obtained from the aminoalcohol-mediated protonation of an enolic species.
\end{abstract}

Keywords: Palladocatalysis, organocatalysis, hydrogenolysis, decarboxylation, ammonium enolate

\section{Introduction}

The asymmetric protonation of prochiral enolic species is an attractive route to prepare optically active carbonyl compounds. ${ }^{1-6}$ Over the past years, we contributed to this topic using various substrates and procedures. ${ }^{7}$ With 2-methyl-2-benzyloxycarbonyl-1-indanone (KE) as the substrate, the procedure, studied in collaboration with Martens team, ${ }^{8,9}$ involves a Pd-catalyzed hydrogenolysis in the presence of an unichiral ${ }^{10} \beta$-aminoalcohol $\left(\mathbf{A H}^{*}\right)$ (Scheme 1). In the present paper, we discuss the nature of the intermediate responsible of the enantioselection, and the result of the reaction occurring with optically active 2-methyl-2-benzyloxycarbonyl-1indanone and an achiral $\beta$-aminoalcohol (AH). 


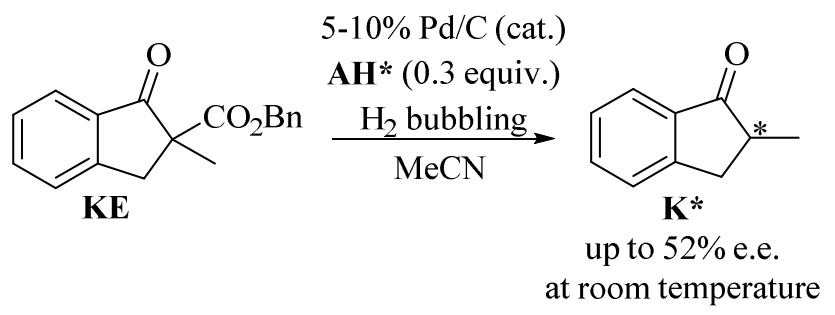

\section{Scheme 1}

\section{Results and Discussion}

In 1994, we proposed that, from KE, the $\mathbf{P d} / \mathbf{A H}^{*}$ procedure leads to optically active 2methylindanone $\left(\mathbf{K}^{*}\right)$ via the asymmetric protonation of an enolic species. ${ }^{8}$ Subsequent studies using different substrates and procedures led us to conclude that the main enolic species involved in the enantioselection is the ammonium enolate ${ }^{\mathbf{A}} \mathbf{E}^{*}$ (Scheme 2). ${ }^{7}$ This latter, which is formed from hydridopalladium $\beta$-ketocarboxylate ${ }^{\mathbf{P d}} \mathbf{K C}$ or/and $\beta$-ketoacid $\mathbf{K A}$ through various pathways, ${ }^{7}$ affords $\mathbf{K} *$ via either an intramolecular proton transfer or an intermolecular reaction with a protic source, especially the aminoalcohol.

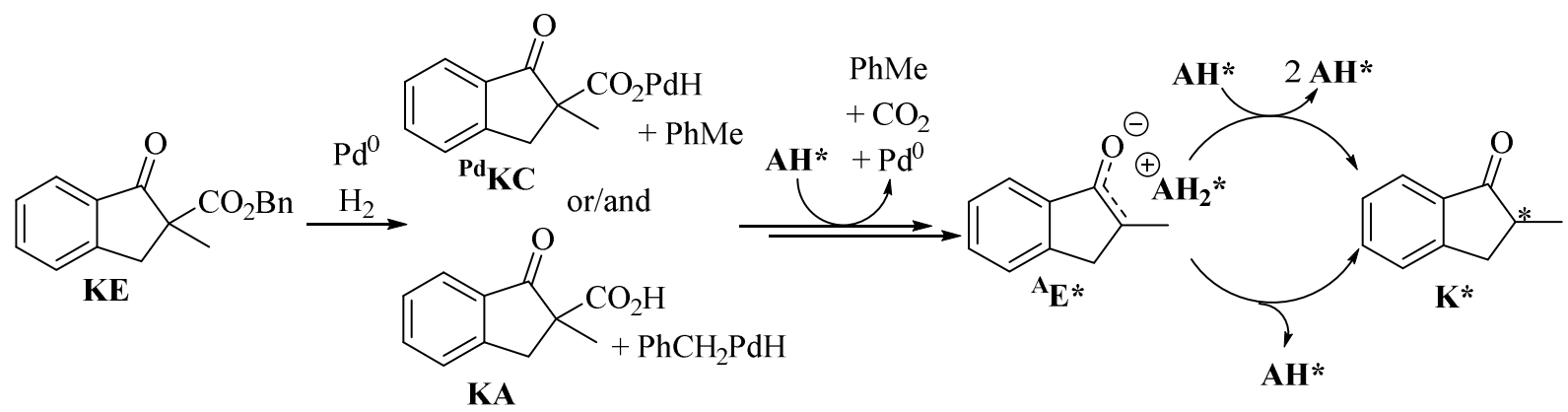

\section{Scheme 2}

In the absence of an aminoalcohol, we revealed that the Pd-catalyzed hydrogenolysis of such benzyl $\beta$-ketoesters affords the ketones via the successive formation of the corresponding $\beta$ ketoacids and enols. ${ }^{11,12}$ Interestingly, Baiker and co-workers showed that the reaction of such a $\beta$-ketoacid with $\mathbf{A H} *$ leads to the corresponding diastereomeric ammonium $\beta$-ketocarboxylates, and that their subsequent evolution towards the ketone proceeds at different rates. ${ }^{13}$ According to these authors, this evolution would implicate the protonation of the ammonium salts by a second molecule of $\mathbf{A H}^{*}$, which would occur from the side opposed to their carboxylate unit and simultaneously with the breaking of the $\mathrm{C}-\mathrm{CO}_{2}$ bond. ${ }^{13}$ They also assumed that the $\mathrm{Pd} / \mathbf{A H} \mathbf{H}_{\text {- }}$ mediated domino reaction of a benzyl $\beta$-ketoester involves the corresponding $\beta$-ketoacid as the 
only intermediate responsible of the enantioselection, and its transformation via their concerted mechanism proposal. ${ }^{13}$

We were not confident in this mechanism of the enantioselective reaction of benzyl $\beta$ ketoesters, which was based on computational studies from Strassner et al. on the enantioselective decarboxylation of a Naproxen intermediate. ${ }^{14}$ Moreover, Brunner and Baur have denied the Strassner proposal. ${ }^{15}$ To remove the ambiguity on the nature of the intermediate which suffers protonation, we studied the hydrogenolysis of optically active 2-methyl-2benzyloxycarbonyl-1-indanone $\left(\mathbf{K E}^{*}\right)$ using an achiral aminoalcohol (AH) as protonating species. ${ }^{16}$ Indeed, the above concerted mechanism would imply a chirality transfer through the protonation of ammonium $\beta$-ketocarboxylate ${ }^{\mathbf{A}} \mathbf{K C} *$ to afford $\mathbf{K}^{*}$ (Scheme 3, path $a$ ), while the formation of ammonium enolate ${ }^{\mathbf{A}} \mathbf{E}$ as intermediate would lead to racemic 2-methylindanone (K) (Scheme 3, path $b$ ). ${ }^{\mathbf{A}} \mathbf{E}$ could be obtained via various pathways, one of them being the decarboxylation of ${ }^{\mathrm{A}} \mathbf{K C} *$ ?

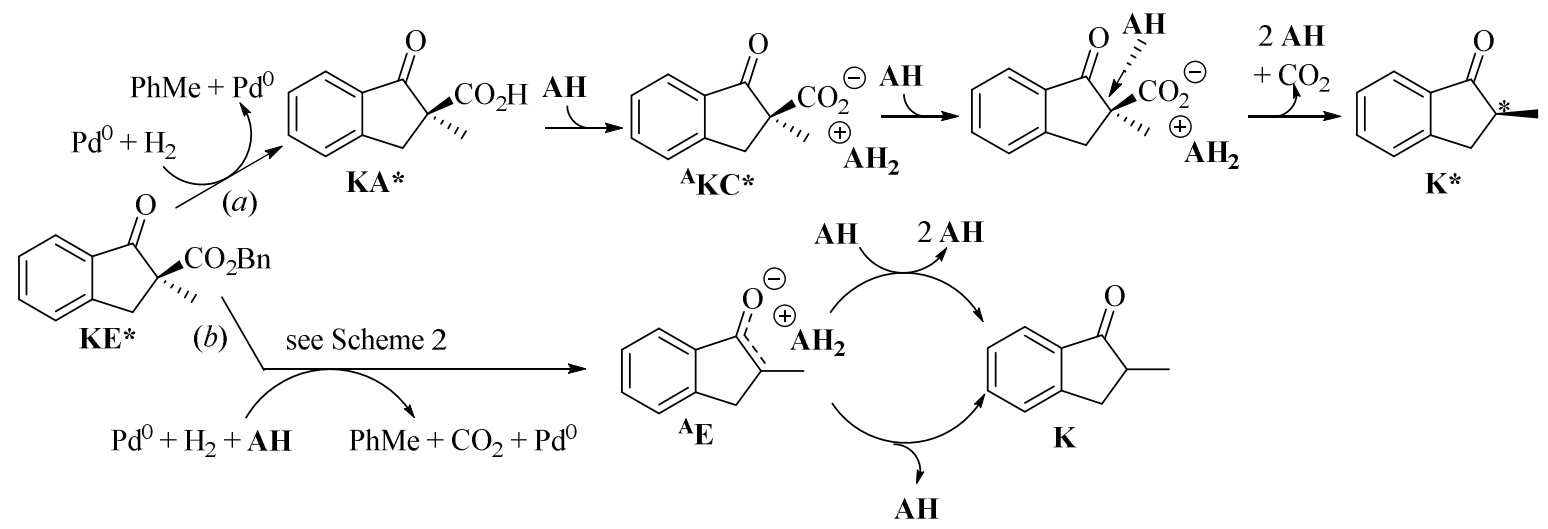

\section{Scheme 3}

The synthesis of $\mathbf{K E}^{*}$ was tentatively carried out via the corresponding chiral ketimines. Using the $\mathrm{TiCl}_{4}$ procedure, ${ }^{17}$ we however observed that the two enantiomers of $\mathbf{K E}$ react with $(S)$ - $\alpha$-methylbenzylamine at different rates. Consequently, this kinetic resolution of $\mathbf{K E}$ has been used to prepare $\mathbf{K E}^{*}$. With a substoichiometric amount of $\mathrm{TiCl}_{4}$ in benzene at $0{ }^{\circ} \mathrm{C}$, $\mathbf{K E}^{*}$ was isolated with $30 \%$ e.e. (Scheme 4).<smiles>CC1(C(=O)OBr)Cc2ccccc2C1=O</smiles>

KE<smiles>C[C@@H](N)c1ccccc1</smiles>

(3 equiv.)

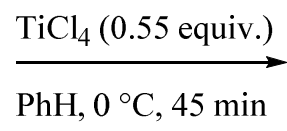

$\mathrm{PhH}, 0^{\circ} \mathrm{C}, 45 \mathrm{~min}$<smiles>CC1(C(=O)Oc2ccccc2)Cc2ccccc2C1=O</smiles>

$\mathbf{K E}^{*}, 30 \%$ e.e.

\section{Scheme 4}


As unichiral $\beta$-aminoalcohols having a secondary amino group were used for the synthesis of $\mathbf{K}^{*}$ from KE, ${ }^{8,9,18}$ the Pd-catalyzed hydrogenolysis of $\mathbf{K E}^{*}$ was carried out with 2(methylamino)ethanol as the protonating species. At room temperature under these conditions, $\mathbf{K E}^{*}$ afforded 2-methylindanone in high yield but without optical activity (Scheme 5). This result highly contrasts with the formation, under similar conditions, of $\mathbf{K}^{*}$ from the hydrogenolysis of $\mathbf{K E}$ in the presence of $\mathbf{A H}^{*}$ (Scheme 1), ${ }^{8,9,18,19}$ and agrees with an enantioselection depending on the asymmetric protonation of the ammonium enolate (Scheme 3, path $b$ ). As the enantioselectivity obtained from KE using the $\mathbf{P d} / \mathbf{A H}^{*}$ procedure depends on the experimental conditions, ${ }^{8,9,18,19}$ we have however to remember that competitive pathways, such as the reductive elimination of $\mathrm{Pd}^{0}$ from hydridopalladium enolate ${ }^{\mathbf{P d}} \mathbf{E}$ and the tautomerisation of enol $\mathbf{E},{ }^{7,18}$ can also lead to $\mathbf{K}$ (Scheme 6).
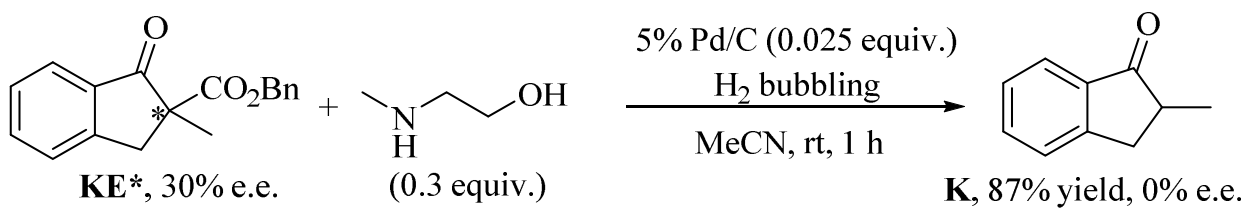

\section{Scheme 5}

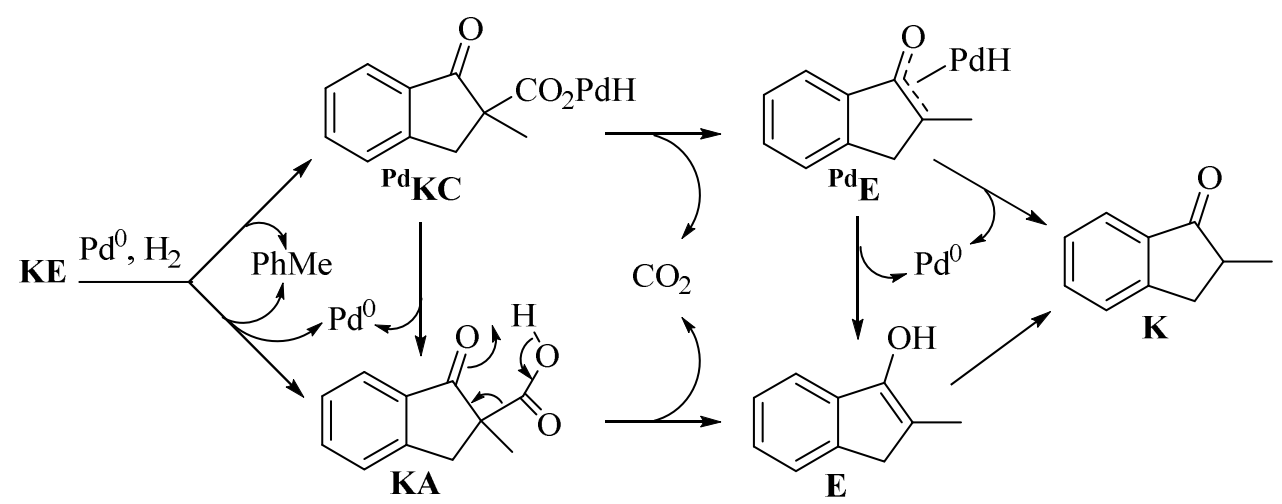

\section{Scheme 6}

\section{Conclusions}

The protonation of an enolic species is involved in the formation of 2-methylindanone from the domino reaction initiated by the Pd-catalyzed hydrogenolysis of 2-methyl-2-benzyloxycarbonyl1 -indanone in the presence of a $\beta$-aminoalcohol. This species is best depicted as the ammonium enolate of 2-methylindanone. ${ }^{7}$ Consequently, when the aminoalcohol is unichiral, the enantioselection depends on the discrimination between the two faces of the corresponding chiral ammonium enolate. 


\section{Experimental Section}

General. 5\% Pd/C was from Engelhard Company Ref. 5011; this catalyst has a surface area of $1100 \mathrm{~m}^{2} / \mathrm{g}$ and contains $50 \%$ of water, the carbon type being activated wood (Technical information from Engelhard Company). Spectroscopic properties of $\mathbf{K}^{20}$ and $\mathbf{K E}^{11}$ have already been described. The enantioselectivities were determined by HPLC using chiral columns from Daicel, eluted with $n$-hexane/isopropanol (9:1), and UV detection at $254 \mathrm{~nm}$.

Preparation of optically active 2-methyl-2-benzyloxycarbonyl-1-indanone (KE*). A 1 M solution of $\mathrm{TiCl}_{4}(0.9 \mathrm{mmol})$ in $\mathrm{CH}_{2} \mathrm{Cl}_{2}$ was added to a solution, at $0{ }^{\circ} \mathrm{C}$, of $\mathbf{K E}^{11}$ (458 $\mathrm{mg}, 1.63$ $\mathrm{mmol})$ and $(S)$ - $\alpha$-methylbenzylamine $(592 \mathrm{mg}, 4.89 \mathrm{mmol})$ in benzene $(10 \mathrm{~mL})$. After stirring at $0{ }^{\circ} \mathrm{C}$ for $45 \mathrm{~min}$, the mixture was concentrated under reduced pressure. Flash-chromatography of the residue, eluted with petroleum ether/ethyl acetate (98:2), led to $\mathbf{K E}^{*}$ (183 $\mathrm{mg}$ ). The enantiomeric excess (30\%) was determined using a Chiralcel OD column (flow rate: 0.5 $\mathrm{mL} / \mathrm{min}$, retention times: 13.2 and $14.4 \mathrm{~min}$ ).

Hydrogenolysis of optically active 2-methyl-2-benzyloxycarbonyl-1-indanone (KE*). To a solution, at room temperature, of $\mathbf{K E}^{*}(30 \%$ e.e., $50 \mathrm{mg}, 0.178 \mathrm{mmol})$ and 2(methylamino)ethanol (4 mg, $0.053 \mathrm{mmol})$ in $\mathrm{MeCN}(4 \mathrm{~mL})$ was added 5\% $\mathrm{Pd} / \mathrm{C}(20 \mathrm{mg})$. A slow stream of hydrogen was immediately bubbled into the stirred mixture. After $1 \mathrm{~h}$, the solvent was evaporated under reduced pressure. Purification of the residue by flash-chromatography eluted with petroleum ether/ethyl acetate (9:1) afforded 2-methyl-1-indanone (24 mg), which was racemic according to its analysis using a Chiralcel OB-H column (flow rate: $0.7 \mathrm{~mL} / \mathrm{min}$, retention times: 13.3 and $19.4 \mathrm{~min}$ ).

\section{References}

1. Fehr, C. Angew. Chem. Int. Ed. Engl. 1996, 35, 2566-2587. http://dx.doi.org/10.1002/anie.199625661

2. Yanagisawa, A., Ishihara, K.; Yamamoto, H. Synlett 1997, 411-420. http://dx.doi.org/10.1055/s-1997-6131

3. Eames, J.; Weerasooriya, N. Tetrahedron: Asymmetry 2001, 12, 1-24. http://dx.doi.org/10.1016/S0957-4166(00)00496-1

4. Duhamel, L.; Duhamel, P.; Plaquevent, J.-C. Tetrahedron: Asymmetry 2004, 15, 3653-3691. http://dx.doi.org/10.1016/S0957-4166(00)00496-1

5. Blanchet, J.; Baudoux, J.; Amere, M.; Lasne, M.-C.; Rouden, J. Eur. J. Org. Chem. 2008, 5493-5506.

http://dx.doi.org/10.1002/ejoc.200800759

6. Mohr, J. T.; Hong, A. Y.; Stoltz, B. M. Nature Chem. 2009, 1, 359-369.

http://dx.doi.org/10.1038/nchem.297 
7. Muzart, J. Tetrahedron: Asymmetry 2014, 25, 697-704.

http://dx.doi.org/10.1016/j.tetasy.2014.02.017

8. Jamal Aboulhoda, S.; Hénin, F.; Muzart, J.; Thorey, C.; Behnen, W.; Martens, J.; Mehler, T. Tetrahedron: Asymmetry 1994, 5, 1321-1326. http://dx.doi.org/10.1016/0957-4166(94)80173-8

9. Jamal Aboulhoda, S.; Reiners, I.; Wilken, J.; Hénin, F.; Martens, J., Muzart, J. Tetrahedron: Asymmetry 1998, 9, 1847-1850.

http://dx.doi.org/10.1016/S0957-4166(98)00189-X

10. The term unichiral, which refers to chiral compounds consisting of a single enantiomer, has been proposed by Gal: Gal, J. J. Chromatogr. 1998, 829, 417-418; Gal, J. Enantiomer 1998, 3, 263-273.

11. Detalle, J.-F.; Riahi, A.; Steinmetz, V.; Hénin, F.; Muzart, J. J. Org. Chem. 2004, 69, 65286532. DOI: $10.1021 /$ jo049464w. http://dx.doi.org/10.1021/jo049464w

12. Riahi, A.; Muzart, J.; Abe, M.; Hoffmann, N. New J. Chem. 2013, 37, 2245-2249. DOI: 10.1039/c3nj00457k. http://dx.doi.org/10.1039/c3nj00457k

13. Kukula, P.; Matoušek, V.; Mallat, T.; Baiker, A. Chem. Eur. J. 2008, 14, 2699-2708. http://dx.doi.org/10.1002/chem.200701652

14. Drees, M.; Kleiber, L.; Weimer, M.; Strassner, T. Eur. J. Org. Chem. 2002, 2405-2410. http://dx.doi.org/10.1002/1099-0690(200207)2002:14<2405::AID-EJOC2405>3.0.CO;2-1

15. Brunner, H.; Baur, M. A. Eur. J. Org. Chem. 2003, 2854-2862. http://dx.doi.org/10.1002/ejoc.200300206

16. The absolute configuration of the used $\mathbf{K E}^{*}$ has not been determined. Thus, the use of $\mathbf{K E}^{*}$ with $(S)$-configuration in Scheme 3 is only to highlight the two plausible reactive pathways.

17. Weingarten, H.; Chupp, J. P.; White, W. A. J. Org. Chem. 1967, 32, 3246-3249. http://dx.doi.org/10.1021/jo01285a088

18. Muzart, J.; Hénin, F.; Jamal Aboulhoda, S. Tetrahedron: Asymmetry 1997, 8, 381-389. http://dx.doi.org/10.1016/S0957-4166(97)84908-7

19. Kukula, P.; Matoušek, V.; Mallat, T.; Baiker, A. Tetrahedron: Asymmetry 2007, 18, 28592868. http://dx.doi.org/10.1016/j.tetasy.2007.11.017

20. Hénin, F.; M’Boungou-M'Passi, A.; Muzart, J.; Pète, J.-P. Tetrahedron 1994, 50, 2849-2864. http://dx.doi.org/10.1016/S0040-4020(01)86998-2 